\title{
DESIGN AND DEVELOPMENT OF TRACTOR CLUTCH USING COMBINED FIELD AND BENCH TESTS
}

\begin{tabular}{|r|l|}
\hline Journal: & Transactions of the Canadian Society for Mechanical Engineering \\
\hline Manuscript ID & TCSME-2017-0032.R1 \\
\hline Date Submitted by the Author: & Ar-Oct-2017 \\
\hline Complete List of Authors: & $\begin{array}{l}\text { Karpat, Fatih; Uludag Universitesi, Department of Mechanical Engineering } \\
\text { Yuce, Celalettin; Uludag Universitesi, Department of Mechanical } \\
\text { Engineering } \\
\text { Dogan, Oguz; Uludag Universitesi, Department of Mechanical Engineering } \\
\text { Genc, Mehmet Onur; Valeo Bursa } \\
\text { Kaya, Necmettin; Uludag Universitesi, Department of Mechanical } \\
\text { Engineering }\end{array}$ \\
\hline $\begin{array}{r}\text { Is the invited manuscript for } \\
\text { consideration in a Special } \\
\text { Issue? : }\end{array}$ & N/A \\
\hline Keywords: & $\begin{array}{l}\text { Tractor field tests, Data collection, Tractor clutch, Product development } \\
\text { process }\end{array}$ \\
\hline &
\end{tabular}

\section{SCHOLARONE ${ }^{\text {'w }}$}

Manuscripts 


\title{
DESIGN AND DEVELOPMENT OF TRACTOR CLUTCH USING COMBINED FIELD AND BENCH TESTS
}

\author{
Fatih Karpat ${ }^{1}$, Celalettin Yuce ${ }^{1}$, Oguz Dogan ${ }^{1}$, Mehmet Onur Genç ${ }^{2}$, Necmettin Kaya ${ }^{1}$ \\ ${ }^{1}$ Department of Mechanical Engineering, Uludag University, Bursa, TURKEY. \\ E-mail: karpat@uludag.edu.tr; karpats@hotmail.com \\ ${ }^{2}$ VALEO Inc., Bursa, TURKEY.
}

\begin{abstract}
Tractors, the primary component of agricultural mechanization, are used actively for maintaining agricultural activities and carrying burdens on agricultural fields under challenging conditions. Tractors are not only required to possess a high tractive force at low operating speeds but also to produce the power necessary for operating the equipment attached to them when used for agricultural purposes. It is of great importance to determine the degree of compulsion that powertrains, especially the clutch, of the tractors are exposed to on agricultural fields and to use the data obtained in this process concerning their guarantee periods. This study measured the motor rotation speed, clutch surface temperature, and frequency and force of pushing the clutch pedal of a tractor used under five different agricultural field conditions. Furthermore, torque and transfer of the dynamometer and power take-off (PTO) were measured. Based on the data obtained from field tests, the tractor clutch development and validation processes were revised. The prototype clutch was produced and tested by completing the required one million rotations safely under new boundary conditions within the guarantee period.
\end{abstract}

Keywords: Tractor field tests, Data collection, Tractor clutch, Product development process 


\section{INTRODUCTION}

In agricultural production, getting the maximum efficacy within a given unit area is based on the level of agricultural mechanization (Ting et al. 2011). Different from other agriculture technology implementations, the use of machines in agriculture impacts the increase in productivity directly and enables to employ new production techniques in rural areas as well. As a primary component of agricultural mechanization, tractors are crucial vehicles used for agricultural activities as well as carrying burdens with the tractor attachments. Different from other vehicles, they can operate in very harsh field conditions. Tractors are required to possess a high tractive force at low operating speeds and to produce the power necessary for their attachments when used on agricultural fields. Given the aforementioned expectations, big technological investments are made for the development of tractors today (Cavallo et al. 2014). Powertrain systems of tractors differ from those of passenger cars, and they constitute approximately $25-30 \%$ of the total tractor manufacture cost. The torque gained from the engine of these vehicles is used both to move the vehicle through transmission and to operate tractor attachments with the help of Power Take-Off (PTO). Because tractor clutches function to arrange the torque distribution, they include two systems running independently or simultaneously in the same unit, unlike other vehicles. Given this function, the clutch is considered to be the most critical part of the powertrain system. Hence, clutch failures not only disable the vehicle but also damage the producing companies' reputation (Ompusunggu et al. 2013).

That tractor clutches manage to perform torque transmissions in big capacities during sudden loading at high operating temperatures is directly related to product life. One of the priorities of the manufacturers is to see the clutch remain intact under the aforementioned conditions within the guarantee period. Numerical analyses and bench tests are made throughout the product design and validation processes of the clutch. The force applied to the clutch and roller bearing expansion displacement is stable during laboratory tests, leading us to define the loading on the clutch as a constant amplitude signal. However, the extent of the force applied to the clutch and the size of displacement vary depending on the operating conditions of the tractor and driver's characteristics. As such, it is important to conduct field tests to identify these values; yet real field tests both increase the cost of product development and extend the validation process. Using the data obtained from the real 
field tests as the boundary conditions in the analyses and laboratory tests may help reduce the total cost by shortening the product development and new product design processing time.

Several researchers in the literature have mostly carried out analytic and experimental studies concerning the clutches of automobiles. However, limited research exists related to tractor field tests in the literature. In their study examining the tractor's processing capacity and sensitivity, Yahya et al. (2006) investigated the compulsions that the tractor went through depending on the geographical conditions and soil cultivation type. Using the sensory devices installed on the tractor, they evaluated the data about the track, depth, and slope of soil, PTO torque transmission, tractive force, and fuel consumption. Kim et al. (2001) performed measurements on transmission box driveshaft and vehicle propeller shaft of tractors operating in five different land conditions at two different speeds and carried out lifespan calculations based on counting algorithms. Bietresato et al. (2012) collected data from three different tractors outfitted with varying equipment in flat and sloping land conditions and calculated the average productivity of the powertrains via the model that they developed. Besides these studies, Karpat et al. (2014) conducted a survey to investigate the effect of thickness and material selection on stress and deformation on tractor clutch's PTO finger mechanism by using finite element analysis. Stress and deformation values which were occurring during the transfer of power in a safe manner were investigated. Dogan et al. (2016) presented a methodology for re-designing a failed tractor transmission component subjected to cyclic loading.

The reviewed literature showed that limited research had been conducted on the performance of tractors based on the data collected from real field conditions and the data rarely concentrated on the product development processes. In particular, the authors failed to encounter studies focusing on the clutch, which is considered the most crucial component of the powertrain system. Therefore, this study aimed to collect data about the tractor clutch in real field conditions. Depending on the motor rotation speed, this study measured clutch surface temperature and frequency and force of pushing the clutch pedal of a tractor used under five different agricultural field conditions. Moreover, the torque transmitted through PTO was measured based on PTO rotation speed. In light of the analysis of the data obtained in this study, a new tractor clutch was designed, and a prototype clutch was produced. 
The prototype clutch was validated under updated test conditions based on the data obtained from field tests.

\section{MATERIAL AND METHOD}

The tractor clutch is mainly comprised of body, pressure plates, diaphragm, discs, and clutch fingers. The body and pressure plates were manufactured from cast material. Holding the mechanism together, the body serves as friction surface area for the inner disc and converts the energy generated during clutch coupling into heat. The pressure plates create friction and press surface areas and take part in absorbing the heat as well. The clutch fingers are the mechanisms that decide which disc should come into contact while clutch coupling. Fig. 1 illustrates the tractor clutch that was used in field tests of this study. The diameter of the clutch is $280 \mathrm{~mm}$; the finger angles are $120^{\circ}$, and the clutch was produced from a DD11 steel plate. The maximum torque capacity is $430 \mathrm{Nm}$ and the maximum clamp load is $10000 \mathrm{~N}$.

Figure 1. Front and rear images of tractor clutch used in the field tests.

The study aimed to collect data about the clutch of a tractor operating in five different field conditions and to use these data during product development processes. The procedures followed in the study are given in Fig. 2. Throughout the tractor field tests, the present study conducted measurements of PTO's torque and rotation speed, motor rotation speed, clutch body surface temperature, and frequency and force of pushing the clutch pedal. The data were measured in seven channels, collected $256 \mathrm{~Hz}$ sampling rate, and recorded real-time during the measurements. The signals coming from all the measurement tools were collected using LMS Scades Mobile data acquisition system and signal conditioner.

Figure 2. Design and validation process flowchart.

The measurement points on the tractor as shown Fig. 3a were carefully designed to serve the product development and validation processes. PTO's torque and rotation speed and motor rotation speed measurements were conducted to quantify the magnitude of the torque generated by the engine and transmitted to PTO and wheels through the clutch when the tractor was operating agricultural activities on the field. M425 Datum - Torque Transducer was used to obtain PTO's torque 
measurement. OJ5114 Photoelectric laser speed sensor was used to measure the motor rotation speed through the pulley on the engine crankshaft. The positions of torque and laser speed sensors on the tractor can be seen in Fig. $3 \mathrm{~b}$ and 3c. Micro-Epsilon Thermometer CTM-3SF22-C3 infrared temperature sensor was used to observe the heat changes with varying amounts of force that the clutch was exposed to. The temperature of the clutch body was measured with the help of this sensor. An infrared temperature sensor was placed stably on the engine block by opening a hole with a $10 \mathrm{~mm}$ diameter that can help the sensor see the clutch with the help of a special bracket (Fig. 3d). Another output that the researchers desired to obtain in the field tests was to investigate the impact of driving characteristics on the use of the clutch. The necessary data input for the product validation processes was provided by determining the frequency of the clutch pedal use under an average driving condition, and the amount of force and displacement applied to the clutch pedal by the driver. The amount of force applied to the clutch pedal by the driver during gearshifts was measured using a TME DAC 2000P force sensor. An LX-PA-15-P10K model displacement sensor was utilized to identify how often the driver used the clutch and whether he used a half clutch or full clutch (Fig. 3e). In addition to the aforementioned measurements, a dynamometer test which measured the effect of PTO on the clutch was conducted to have the tractor clutch's PTO part forced. Table 1 gives technical information about the instruments used for the measurements.

Figure 3. a) The measurement points on the tractor. b) PTO torque sensor c) Laser speed sensor d) Infrared temperature sensor e) Displacement sensor

Table 1. Measurement instruments and their technical features.

All the field tests were carried out on the test track located in the Başak Tractor Factory in Sakarya. Test conditions were specified considering real field conditions that the tractor may experience while executing agricultural activities and given Table 2. Firstly, in the standard driving test done on the straight road, the test aimed to determine the driver characteristics and clutch performance when the tractor was used for only burden-carrying purposes without considering any agricultural activities. Secondly, in the standard driving test carried out on the field, only the tractor's performance was simulated without any tractor attachments. Thirdly, the responses of the driver and the clutch were 
examined during the execution of an agricultural activity on the filed-a hoeing test with the tractor plough. The hoeing plough was chosen given that it is one of the most difficult agricultural activities. Fourthly, Test 4 was designed to aggravate the previous test condition through the frequent use of the clutch. Finally, the tractor's performance under harsher conditions using the clutch frequently on a slightly sloped and rocky road was investigated in Test 5 . In addition to the aforementioned tests, in Test 6, clutch performance was measured by connecting PTO shaft to a dynamometer while only the PTO function of the clutch was working (the tractor was stable).

Table 2. The conditions of the tractor tests.

\section{RESULTS AND DISCUSSION}

\subsection{Field Test Results}

The temperature values obtained from the tests results shown in Fig. 4. The highest clutch surface temperature was observed in Test 5 and went up to $160^{\circ} \mathrm{C}$ at its maximum. The temperature value was measured around $120^{\circ} \mathrm{C}$ during frequent use of the clutch while hoeing with the plough (Test 4) and during the PTO dynamometer measurement test (Test 6). While the temperature value was recorded around $100^{\circ} \mathrm{C}$ during hoeing activity with the tractor plough (Test 3), in the driving tests on the straight road and the field without any tractor attachments (Test 1 and Test 2), the clutch did not heat more compared to other situations. According to the test results, frequent use of the clutch under the same conditions increased the temperature significantly.

Figure 4. Maximum temperature values measured on the clutch surface in different tests.

As can be seen in Fig. 5, time-based instant changes of the surface temperatures measured when the clutch temperature was at its maximum and minimum values were given in an 800 -second sampling period. Figure 5(a) shows the time-based instant change of clutch surface temperature in Test 1 where the minimum temperature value was measured. Fig. 5(b), however, illustrates the time-based instant change of clutch surface temperature in Test 5 where the maximum temperature value was measured. When the clutch temperature curve was examined, it was noted that temperature values did not increase much under driving conditions on the straight road and the maximum temperature was 
measured as $54^{\circ} \mathrm{C}$. On the other hand, the tractor clutch was tested under extremely harsh conditions in Test 5. After a 700-second high-performance period in the test, the clutch was allowed to cool by leaving the motor open to see the cooling speed of the clutch at idling speed. As a result, the clutch surface temperature went up to $160^{\circ} \mathrm{C}$ under these conditions, and steady-state temperature regime was obtained. Afterward, the clutch was observed to cool down to $110^{\circ} \mathrm{C}$ within a 700 -second period.

Figure 5. Clutch surface temperature changes under different samples (a) Test 1 and (b) Test 5.

Another set of data measured in this study was the frequency of clutch pedal pushing and the number of repeats of clutch use within a particular period. In this way, the study aimed to identify driving characteristics. The results aimed to determine the number of repeats that the tractor clutch fingers would have and which types of loadings would cause the repeats within the guarantee period. Additionally, these data can be used as input data for fatigue test analyses and bench tests. The maximum amount of displacement applied to the clutch was found to be $190 \mathrm{~mm}$, and a displacement of nearly $110 \mathrm{~mm}$ with a maximum number of 65 repeats applied to the clutch by the driver was observed in Test 1 (Fig 6a). Consequently, the driver was found to apply a stable amount of displacement every time in this case. According to the results obtained in Test 2, a $50 \mathrm{~mm}$-distance of clutch displacement was repeated 140 times by the driver (Fig. 6b). These results indicate that the necessity of pushing and releasing the clutch pedal halfway with a short stroke- known as a halfclutch-increases under field conditions. Therefore, the clutch is expected to be forced much more under field conditions.

Clutch pedal pushing frequency and clutch pedal pushing distance was measured in Test 3. According to these results, the clutch use frequency was significantly lower while the tractor was operating with the plough on the field (Fig. 6c). Six repeats were observed for each clutch pedal pushing distance. Since the pushing frequency was lower, the clutch temperature did not increase as much as it did in other test scenarios. Another finding obtained in this test result was that the cooling speed of the clutch was higher than the heating speed. For the clutch to produce heat, it should be used more than a certain number of intervals.

Figure 6. Clutch pushing frequency - displacement graph (a) Test 1, (b) Test 2 and (c) Test 3. 
The clutch was forced into Test 4. As such, a higher frequency of clutch pedal pushing was observed in cases where the clutch displacement was lower (Fig. 7a). The most difficult case was simulated for the tractor clutch in Test 5. Because half-clutch driving conditions were at stake, the maximum frequency of clutch pedal pushing was obtained in cases where the pedal displacement ranged between the values of $80-120 \mathrm{~mm}$ (Fig. $7 \mathrm{~b}$ ). The clutch pedal pushing frequencies were quite low with the other displacement values.

Figure 7. Clutch pushing frequency-displacement graph (a) Test-4 and (b) Test-5.

The amount of clutch pushing force showed instant changes depending on clutch pushing frequency and driving conditions. The maximum clutch pedal pushing force values are given in Table 3. A dynamometer test was also conducted in this research context. This test merely measured the torque transmitted by the PTO shaft when the tractor was stable. The PTO shaft was connected to a dynamometer and forced by exposing a higher level of torque than a compelling attachment could produce. The maximum torque value that the PTO shaft was exposed to was $1345 \mathrm{Nm}$. In this way, clutch performance was measured. Time-based torque fluctuation is illustrated in Fig. 8.

Table 3. The maximum clutch pedal pushing force values.

Figure 8. Time-based torque values exposed through dynamometer - Test 6.

The clutch surface temperature was observed to increase based on the magnitude of the torque (Fig. 9). The clutch was exposed to a maximum loading of $1345 \mathrm{Nm}$ after the 200th second, and this exposure was maintained until the 600th second. This continuous loading increased the clutch surface temperature to approximately $110^{\circ} \mathrm{C}$, and a steady-state temperature regime was reached.

Figure 9. Time-based clutch surface temperature change - Test 3.

\subsection{Product Development and Verification Results}

In the second phase of the study, a new clutch design was completed in light of the data obtained from the field tests and validation studies were conducted under the revised analysis and test conditions based on the data gathered from the field tests. The design and analysis of boundary conditions of the finger mechanism were formed primarily based on the data acquired in the field tests. Initially, the clutch PTO finger was designed (Fig. 10). After the completion of the design, finger 
mechanism was tested by stress analysis within a finite element method in the design validation phase. Mesh construction and boundary conditions attained in the analysis conducted using ANSYS Simulation Software Program (Fig. 11). The boundary conditions required for the finger analysis are defined in three steps. First, a spring with diaphragm-spring features was defined on the finger. The rigidity curve of this spring was attained from the clutch diaphragm spring rigidity curve. Second, the holes through which the finger was assembled on the clutch were defined as support. Only movements in tangential directions were allowed in this area. Other movements in radial and axial directions were defined as zero. Last, the part representing the pressure bearing was moved so that it can pressure the finger only and frictional contact was defined between the bearing model and finger model. The model necessary for the analysis was modeled in CATIA CAD Software and transferred to ANSYS program. The mesh topology of the model is comprised of 52300 hexahedral elements and 219000 nodal points (Fig. 11).

Figure 11. PTO finger mechanism CAD models (a) failed first design and (b) new design.

Figure 11. Static analysis boundary conditions of PTO finger.

According to the results of the static analysis, the maximum stress values were found to be between 25-29 MPa and varied between 70-75 MPa (Fig. 12). As a result of the static analysis, fatigue analysis was made for the finger using ANSYS fatigue module. The results showed that any particular damage on the finger did not occur.

Figure 12. New finger mechanism FEA (a) stress results and (b) fatigue result.

Based on the inferences made out of the results, the clutch case cover, which was impacting most of the heat produced when the clutch was working, was also re-designed. The body of the clutch which originally had three supports for the finger mechanism was redesigned with six supports. The impact of the heat was decreased by designing the new case cover much lighter than the original one and convenient for better air-flow. Fig. 13 displays the newly designed clutch case cover that was used in the field tests.

Figure 13. Clutch case cover (a) conventional design and (b) new design.

After completing the improvement and validation of clutch case cover and finger mechanism designs, the prototype clutch was produced. The new clutch was designed with $310 \mathrm{~mm}$ diameter and 
greater thermal capacity. The supports to which the fingers were connected were distributed to create the 60 -degree angle. In this way, the bearing could move more symmetrically. The finger mechanism was produced from a DD14 steel plate. To prevent surface erosion, the end points of the fingers were sintered. The new clutch had a maximum torque capacity of $500 \mathrm{Nm}$, and a maximum clamp load of $12000 \mathrm{~N}$. The new prototype clutch and conventional clutch that was used in the field tests can be seen in Fig. 14.

Figure 14. The image of the clutch (a) used in the field tests and (b) the new prototype clutch.

The prototype clutch which was validated with the FEA results was validated in the bench tests which was revised based on the results obtained from the field tests. In particular, the life tests of the fingers - the critical part of the clutch —were done within the axial fatigue test setup. Boundary conditions of the test and loading situations were determined depending on the results achieved in the field tests. The axial fatigue test setup can be seen in Figure 15. In this test design, the bearing part was tested for fatigue resistance by applying repetitive loading on the finger at $1 \mathrm{~Hz}$ frequency.

Figure 15. Clutch (a) axial fatigue test setup and (b) tension points measured through the finger mechanism.

The finger mechanism whose design was validated with FEA was subjected to fatigue test, and stress values for the first 300 rotations through the finger were recorded with the help of a strain-gauge (Fig. 15b). The PTO finger was assessed with FEA for the aforementioned boundary conditions, and the results were compared to stress test results. In the comparison, it was found that FEA results corresponded to those of the fatigue test. Time-based changes to the stresses obtained from the straingauges (numbered 1 and 2) placed on the finger were given in graph form in Fig. 16. These values were obtained through the axial fatigue test setup, in line with the pushing frequencies, the amount of pushing stroke, and the clutch pedal force values acquired from the field tests. Given that the system works in a manner of pushing and pulling movements, vibratory loading occurs. As such, stress values vary between the minimum and maximum points constantly. As for the former point, the maximum stress value observed through 300 rotations was measured around 25-27 MPa. However, as for the latter point, the maximum stress value was found to be between 70-80 MPa for 300 rotations similarly.

Figure 16. Stress distribution in the axial fatigue test (a) first point and (b) second point. 
After the stress value measurements, the system was worked until it reached 1 million rotations, and the researchers observed whether any fatigue damage occurred through the system. No damage was found on the fingers after the completion of one million rotations. Only erosions in small quantities occurred on the bearing surface. The image of the prototype clutch and the fingers following the completion of 1 million rotations was given in Fig. 17.

Figure 17. Image of the clutch after the one million rotations.

\section{CONCLUSION}

This study collected data related to tractor clutch performance under different driving characteristics and in five different field conditions. According to the analysis of the test data, a set of values such as an average clutch surface temperature, frequency, and force of clutch pedal pushing according to the conditions that a tractor may experience in daily operations were obtained. The test data were used in the design and validation processes of the new prototype clutch.

The results indicated that field conditions, agricultural activities, and driving characteristics had an important impact on the clutch. It was determined that the clutch was frequently used in the field conditions and it was compelled at its maximum level on the rocky road, resulting in maximum surface temperature values. Additionally, the driver was found to apply a stable displacement to the clutch on the flat road. Furthermore, the results showed that the force of clutch pedal pushing differed based on driving conditions and the maximum pedal pushing force value was $291.3 \mathrm{~N}$ while the minimum value appeared to be $233.4 \mathrm{~N}$. The clutch body temperature was observed to reach a steadystate regime when exposed to maximum loading in the dynamometer test in which the clutch performance was tested when the torque acquired from the motor was transmitted only to the PTO.

The results attained from the field tests were used as input data for test benches in the finite element analyses through the product development processes. In light of the data, the new clutch was designed, and the prototype was produced. The new clutch has a relatively more robust design and can be a solution to the main guarantee return problems — such as finger erosions, finger breakdowns, and slipping because of crooked pressure - with its case cover designed adjacently in 60-degree finger angles. Moreover, a clutch with high thermal capacity was developed thanks to the extended cover 
diameter and the spaces opened on the cover. Also, the newly-designed clutch has a higher maximum clamp load and torque capacity. This enables long-term usage by providing a high safety factor rate. Fatigue analyses and axial fatigue tests of the prototype clutch were conducted, and the results were found to be compatible. The clutch developed in this research completed one million rotations without damage in the axial fatigue tests within real field contexts and boundary conditions.

\section{ACKNOWLEDGEMENTS}

This research paper was written based on the project carried out by Uludağ University and Valeo Inc., numbered 0456.STZ.2013-2, and named "Design and prototype production of the clutch with high torque transmission for new generation tractors." As the authors, we present our thanks to the Ministry of Science, Industry, and Technology of the Republic of Turkey and to Başak Tractor Factory located in Sakarya for contributing to the study with the tractor and test fields.

\section{REFERENCES}

Bietresato, M., Friso, D., and Sartori, L. 2012. Assessment of the efficiency of tractor transmissions using acceleration test. Biosystems Engineering. 112:171-180. doi: 10.1016/j.biosystemseng.2012.03.009.

Cavallo, E., Ferrari, E., Bollani, L. and Coccia, M. 2014. Attitudes and behavior of adopters of technological innovations in agricultural tractors: A case study in Italian agricultural system. Agricultural Systems. 130: 44-54. doi: 10.1016/j.agsy.2014.05.012.

Dogan, O., Karpat, F., Yuce, C., Kaya, N., Yavuz, N. and Sen, H. 2016. A novel design procedure for tractor clutch fingers by using optimization and response surface method. Journal of Mechanical Science and Technology. 30: 2615-2625. doi: 10.1007/s12206-016-0522-x.

Karpat, F., Dogan, O., Yuce, C., Kaya, N., and Cengiz, G. 2014. The investigation of stress distribution on the tractor clutch finger mechanism by using finite element method. Proceedings of 
the ASME 2014 International Mechanical Engineering Congress and Exposition, November 1420, 2014, Montreal, Quebec, Canada.

Kim, D.C., Ryu, I.H. and Kim U.K. 2001. Analysis of tractor transmission and driving axle loads. Transactions of the ASABE. 44(4): 751-757. doi: 10.13031/2013.6236.

Ompusunggu, A.P., Papy, J.M., Vandenplas, S., Sas, P. and Brussel, H.V. 2013. A novel monitoring method of wet friction clutches based on the post-lock up torsional vibration signal. Mechanical Systems and Signal Processing. 35: 345-368. doi: 10.1016/j.ymssp.2012.10.005.

Ting, K.C., Abdelzaher, T., Alleyne, A. and Rodriguez, L. 2011. Information technology and agriculture global challenges and opportunities. The Bridge - Linking Engineering and Society. 41(3): 6-13.

Yahya, A. and Zohadie, M. 2006. Precision system for mapping terrain trafficability, tractorimplement performance and tillage quality. The Institution of Engineers Malaysia. 67(4):56-63. 


\section{Figure captions}

Figure 1. Front and rear images of tractor clutch used in the field tests.

Figure 2. Design and validation process flowchart.

Figure 3. a) The measurement points on the tractor. b) PTO torque sensor c) Laser speed sensor d) Infrared temperature sensor e) Displacement sensor

Figure 4. Maximum temperature values measured on the clutch surface in different tests.

Figure 5. Clutch surface temperature changes under different samples (a) Test 1 and (b) Test 5.

Figure 6. Clutch pushing frequency - displacement graph (a) Test 1, (b) Test 2 and (c) Test 3.

Figure 7. Clutch pushing frequency-displacement graph (a) Test-4 and (b) Test-5.

Figure 8. Time-based torque values exposed through dynamometer - Test 6 .

Figure 9. Time-based clutch surface temperature change - Test 3.

Figure 10. PTO finger mechanism CAD models (a) failed first design and (b) new design.

Figure 11. Static analysis boundary conditions of PTO finger.

Figure 12. New finger mechanism FEA (a) stress results and (b) fatigue result.

Figure 13. Clutch case cover (a) conventional design and (b) new design.

Figure 14. The image of the clutch (a) used in the field tests and (b) the new prototype clutch.

Figure 15. Clutch (a) axial fatigue test setup and (b) tension points measured through the finger mechanism.

Figure 16. Stress distribution in the axial fatigue test (a) first point and (b) second point.

Figure 17. Image of the clutch after the one million rotations. 
Table 1. Measurement instruments and their technical features.

\begin{tabular}{|c|c|c|c|}
\hline $\begin{array}{l}\text { Name of the } \\
\text { instrument/sensors }\end{array}$ & Specification & Origin & Application \\
\hline $\begin{array}{l}\text { LMS Scadas Mobile } \\
\text { SCM05 Data Acquisition } \\
\text { System }\end{array}$ & Accommodates 4 to 40 Channels & Germany & Data storage \\
\hline $\begin{array}{l}\text { LMS Scadas Signal } \\
\text { Conditioner Card }\end{array}$ & $\begin{array}{l}\text { High quality 7-pin LEMO } \\
\text { Connectors } \\
\text { Input Mode Selectable Per Channel } \\
\text { Programmable Bridge Supply up to } \\
\text { 10VDC }\end{array}$ & Germany & Data acquisition \\
\hline $\begin{array}{l}\text { Datum - Torque } \\
\text { Transducer }\end{array}$ & $\begin{array}{l}\text { Torque Range: } 0-1800 \mathrm{Nm} \text {, } \\
\text { precision } 5.556 \mathrm{mV} / \mathrm{Nm} \text {, Velocity } \\
\text { Range: } 0-1000 \mathrm{rpm} \text {, precision } 10 \\
\mathrm{mV} / \mathrm{rpm}\end{array}$ & UK & $\begin{array}{l}\text { PTO Shaft Torque and } \\
\text { Rotation Speed } \\
\text { Measurement }\end{array}$ \\
\hline $\begin{array}{l}\text { Micro-Epsilon Infrared } \\
\text { Temperature Sensor }\end{array}$ & $\begin{array}{l}\text { Range: } 50-400^{\circ} \mathrm{C} \text {, Precision: } \\
14.2857 \mathrm{mV} /{ }^{\circ} \mathrm{C}\end{array}$ & USA & $\begin{array}{l}\text { Clutch Surface } \\
\text { Temperature } \\
\text { Measurement }\end{array}$ \\
\hline $\begin{array}{l}\text { IFM Electronic } \\
\text { Photoelectric Sensor }\end{array}$ & $\begin{array}{l}\text { Measurement Frequency: 0-2000 } \\
\text { Hz, Detection Range: } 8 \text { m }\end{array}$ & Germany & $\begin{array}{l}\text { Motor Rotation Speed } \\
\text { Measurement }\end{array}$ \\
\hline $\begin{array}{l}\text { TME DAC 2000P Force } \\
\text { Sensor }\end{array}$ & Range: $0-500 \mathrm{~N}$ & France & Clutch Pedal Force \\
\hline $\begin{array}{l}\text { Unimeasure LX-PA-15- } \\
\text { P10K Encoder }\end{array}$ & Range: $0-380 \mathrm{~mm}$ & USA & $\begin{array}{l}\text { Clutch Pedal } \\
\text { Displacement }\end{array}$ \\
\hline
\end{tabular}


Table 2. The conditions of the tractor tests.

\begin{tabular}{ll}
\hline Test No & Field and Driving Characteristics \\
\hline 1 & Standard driving test on a straight road (no agricultural activity) \\
2 & Standard driving test on a field (no agricultural activity) \\
3 & Hoeing test with a plough \\
4 & Frequent use of the clutch while hoeing with a plough \\
5 & Frequent use of the clutch on a slightly sloped and rocky road \\
6 & PTO Dynamometer measurement test \\
\hline
\end{tabular}


Table 3. The maximum clutch pedal pushing force values.

\begin{tabular}{lc}
\hline Test No & Maximum Pedal Force $(\mathrm{N})$ \\
\hline Test-1 & 269.92 \\
Test-2 & 271.5 \\
Test-3 & 233.4 \\
Test-4 & 291.3 \\
Test-5 & 276.5 \\
Test-6 & None \\
\hline
\end{tabular}




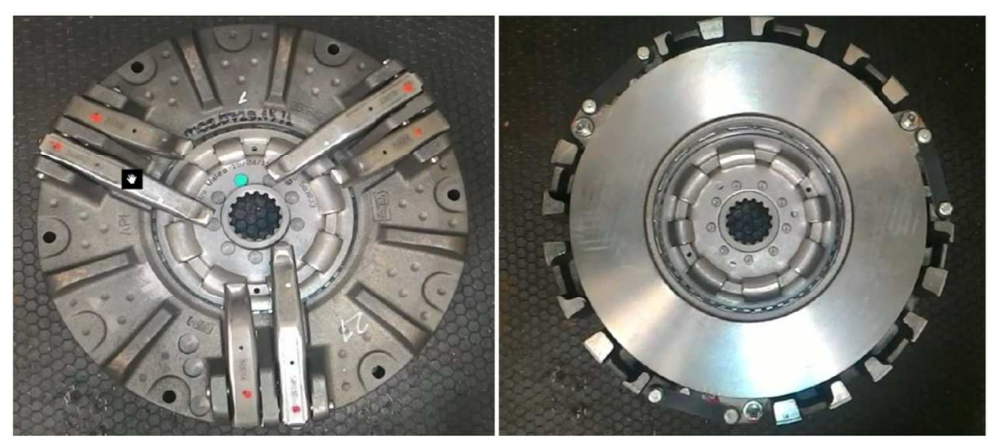

Figure 1 


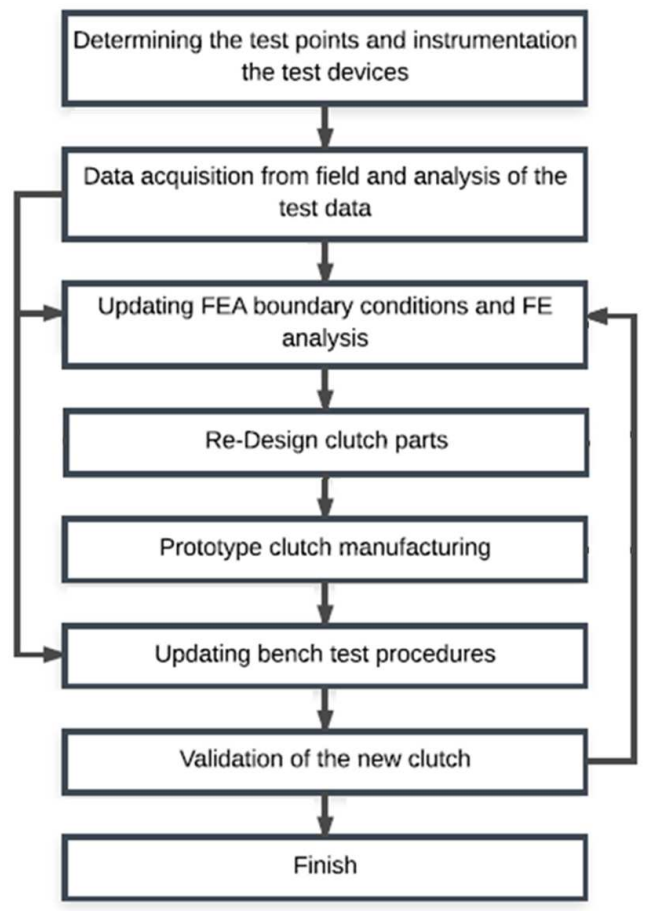

Figure 2. 


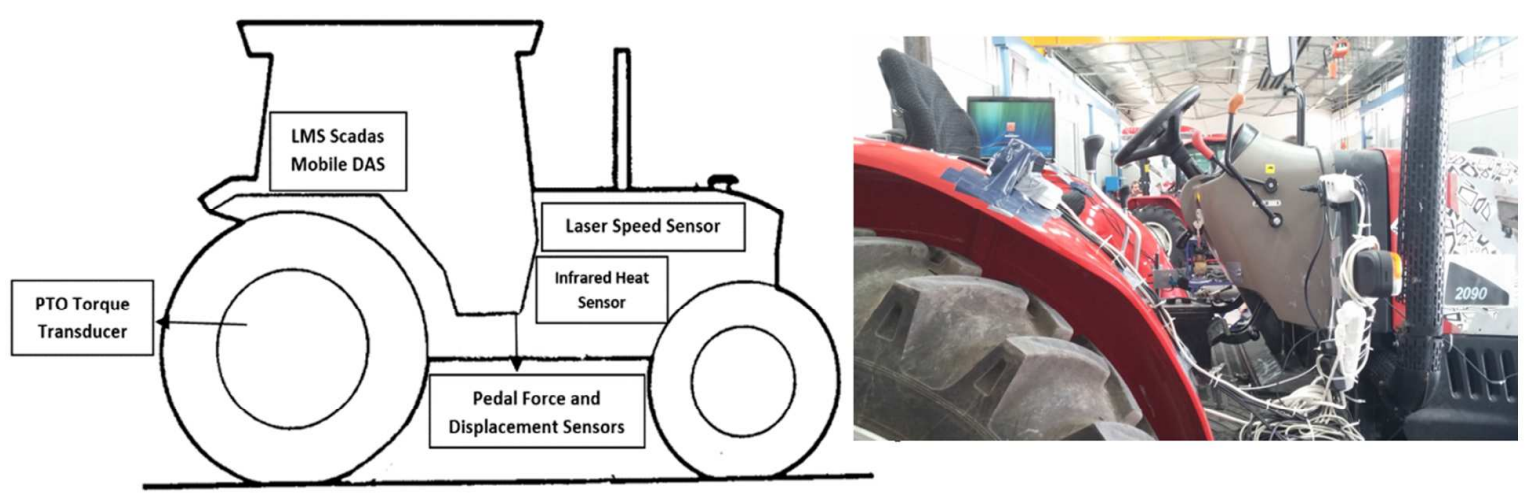

a)

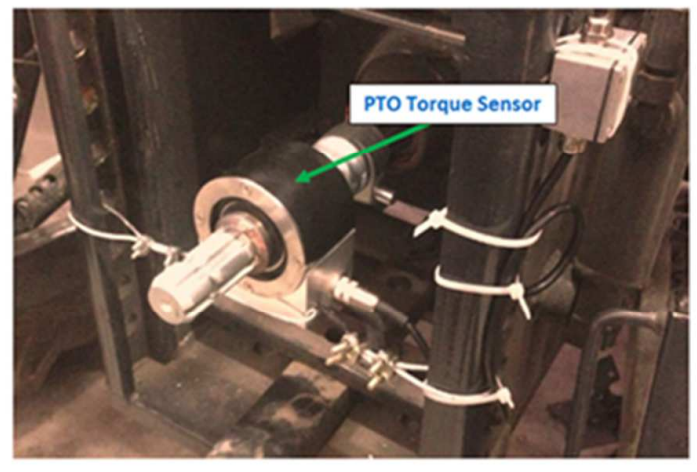

b)

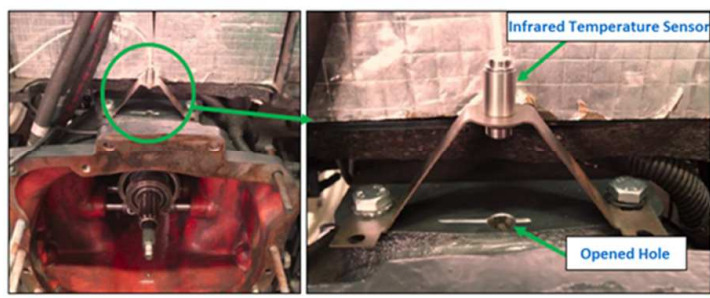

d)

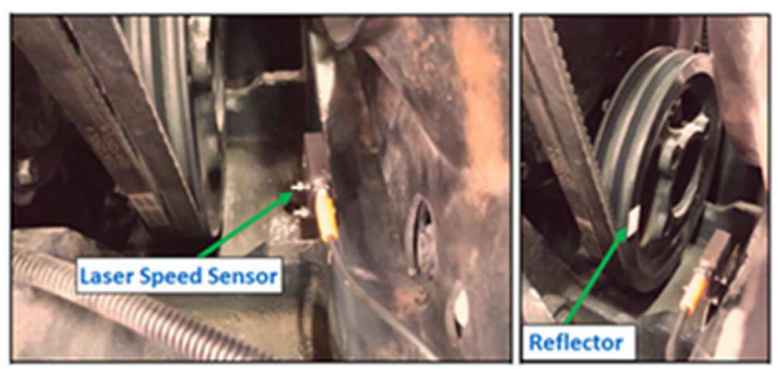

c)

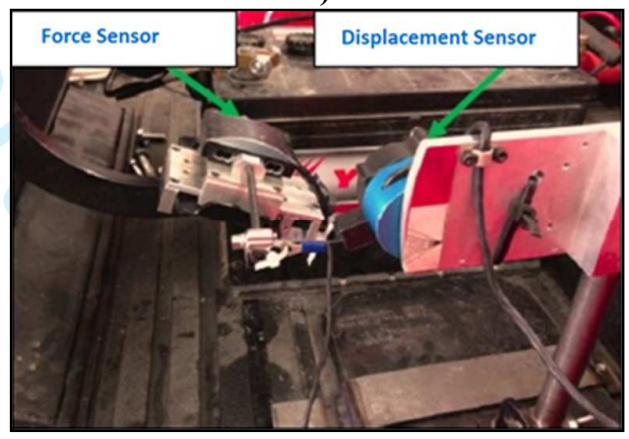

e)

Figure 3. 


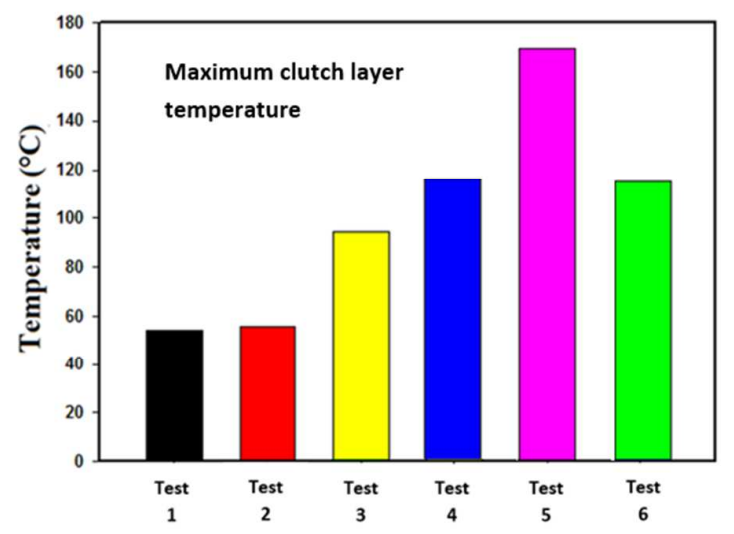

Figure 4. 


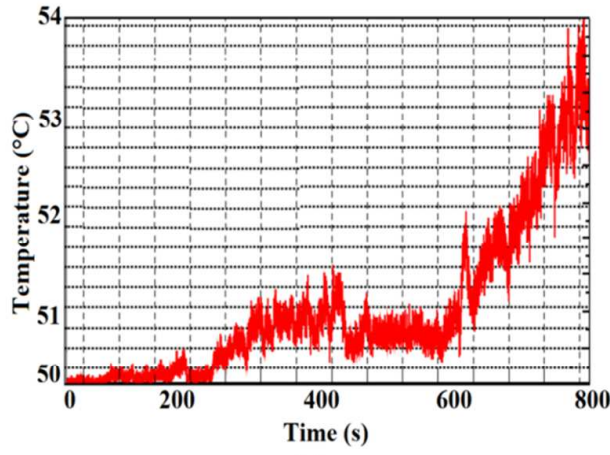

(a)

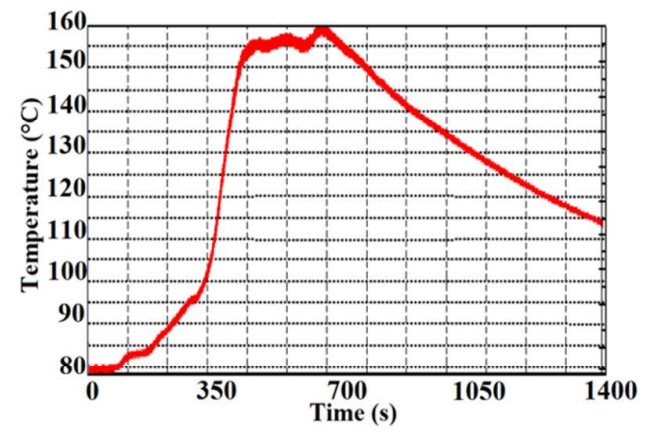

(b)

Figure 5. 


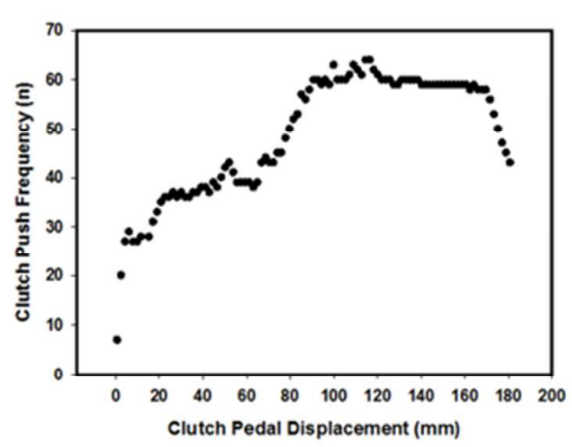

(a)

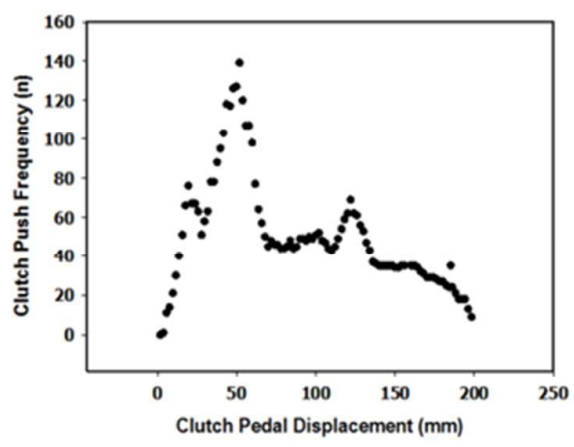

(b)

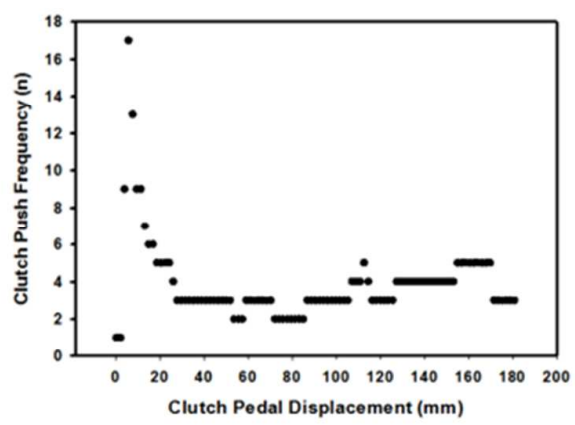

(c)

Figure 6. 


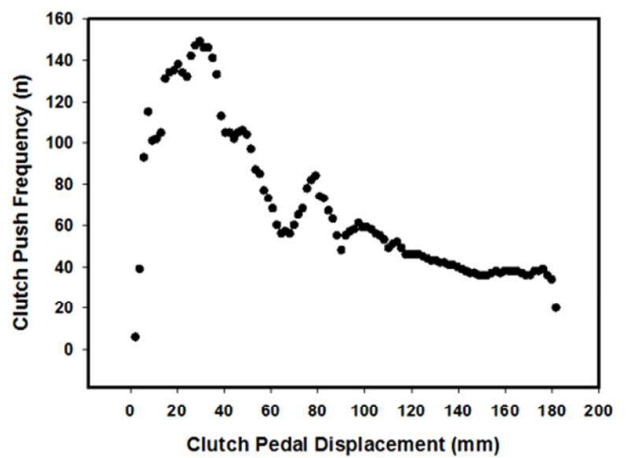

(a)

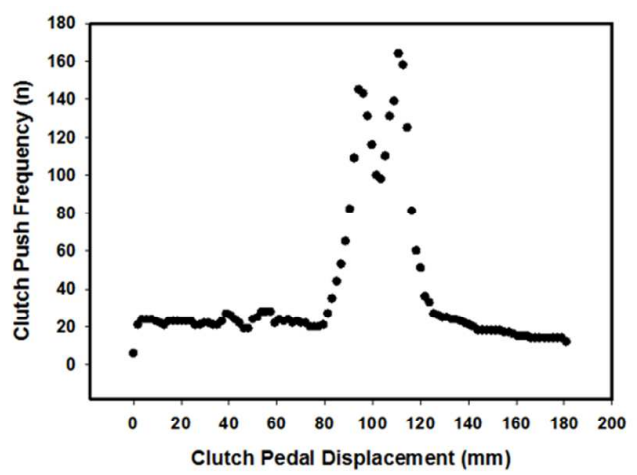

(b)

Figure 7. 


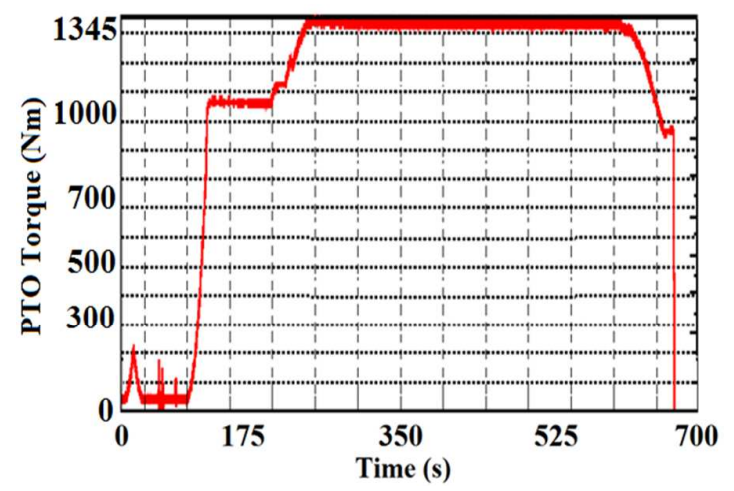

Figure 8. 


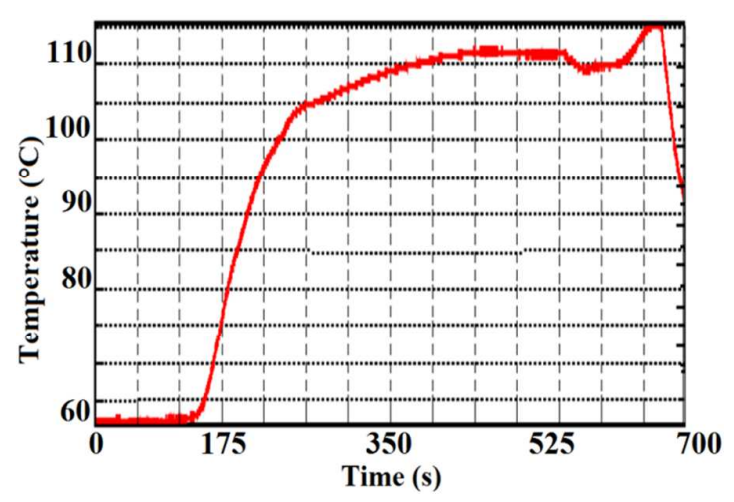

Figure 9. 


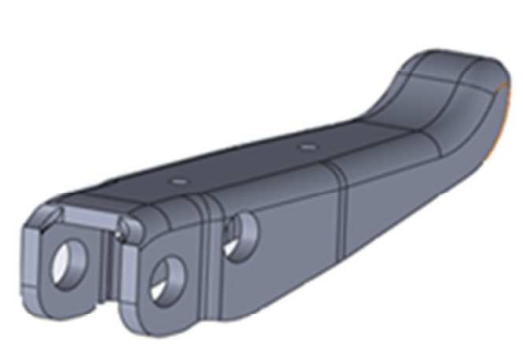

(a)

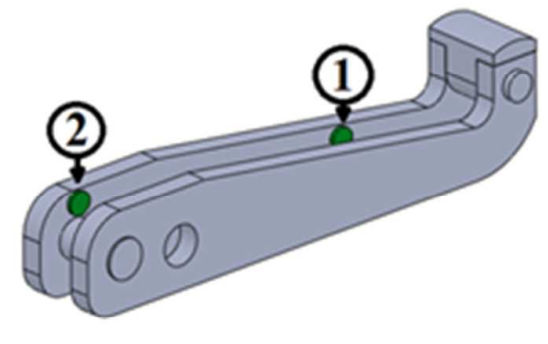

(b)

Figure 10. 


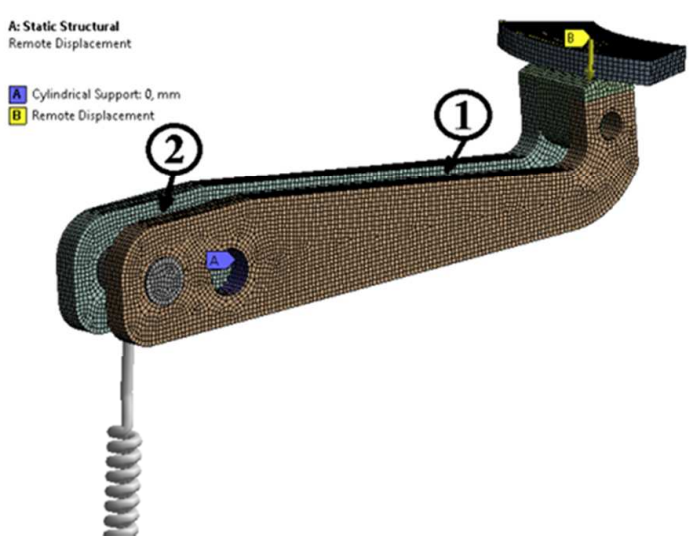

Figure 11. 


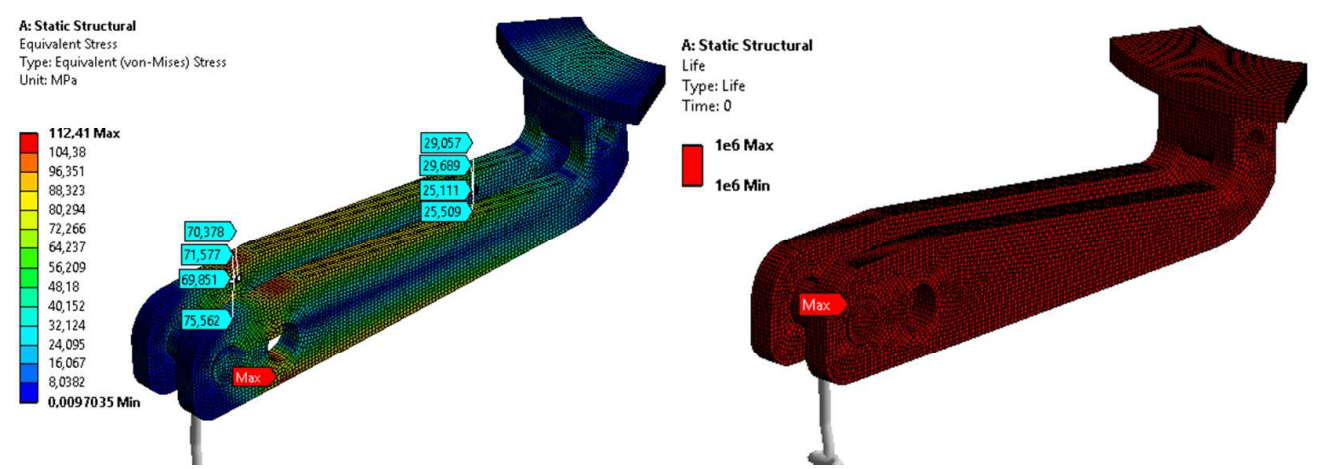

Figure 12. 


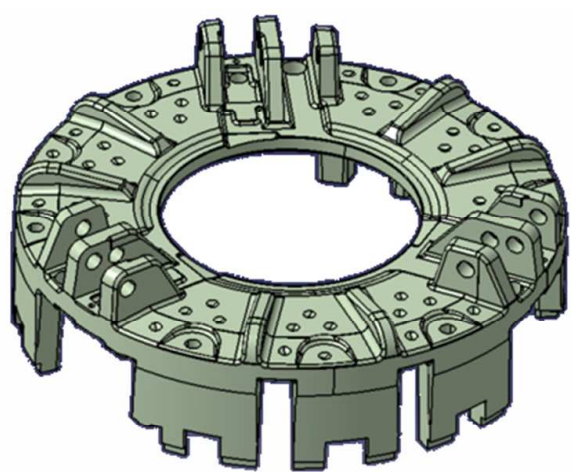

(a)

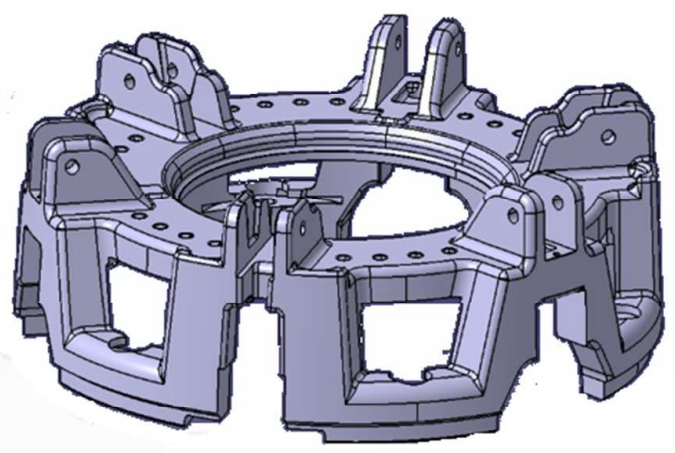

(b)

Figure 13. 


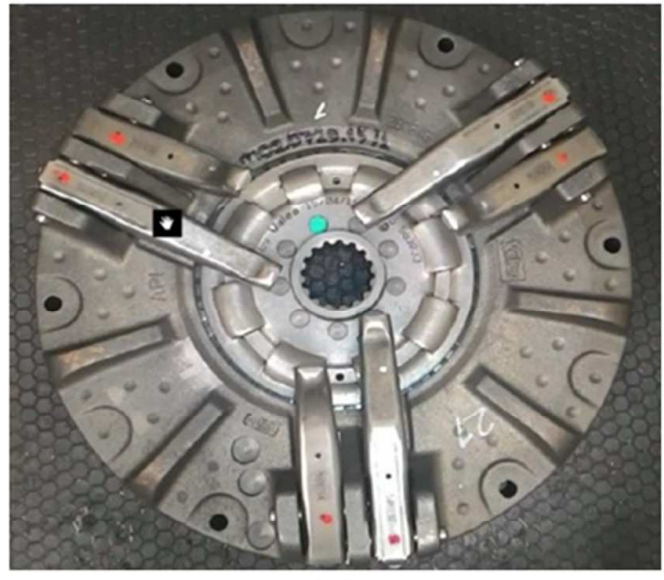

(a)

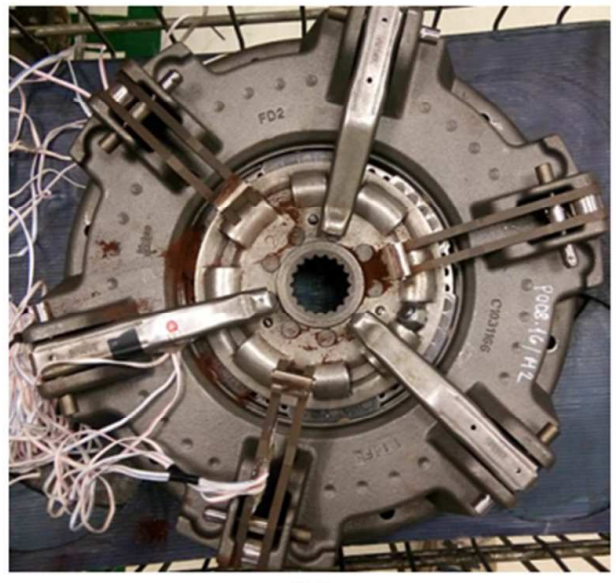

(b)

Figure 14. 


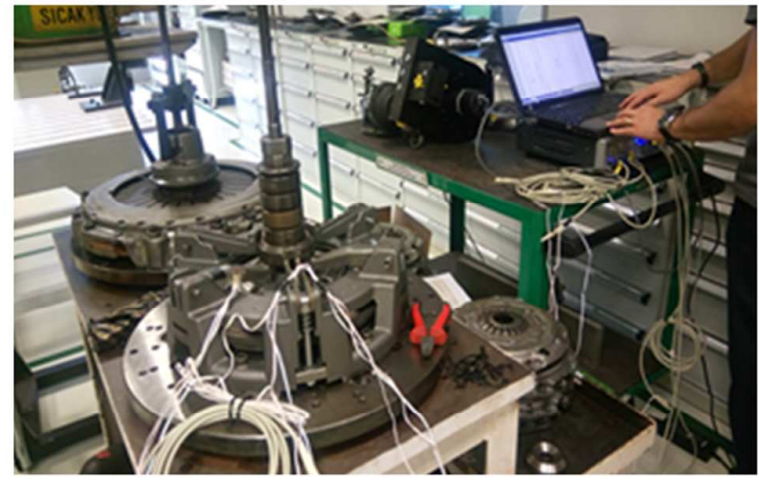

(a)

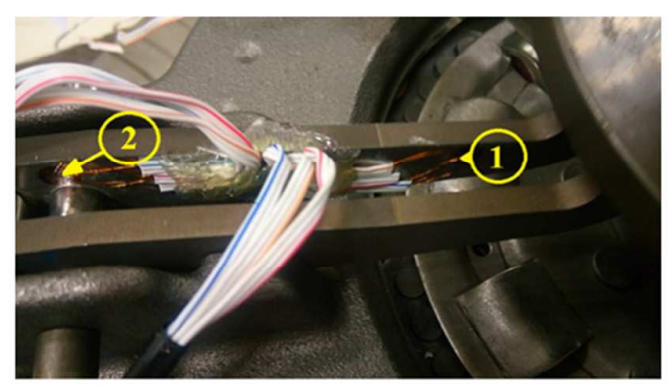

(b)

Figure 15. 


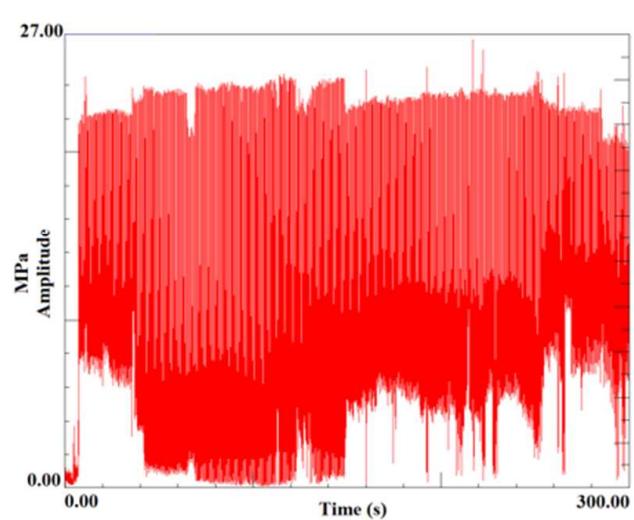

(a)

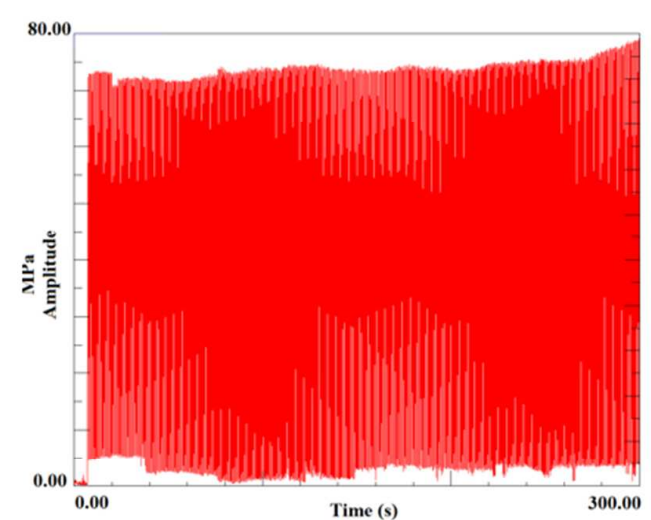

(b)

Figure 16. 


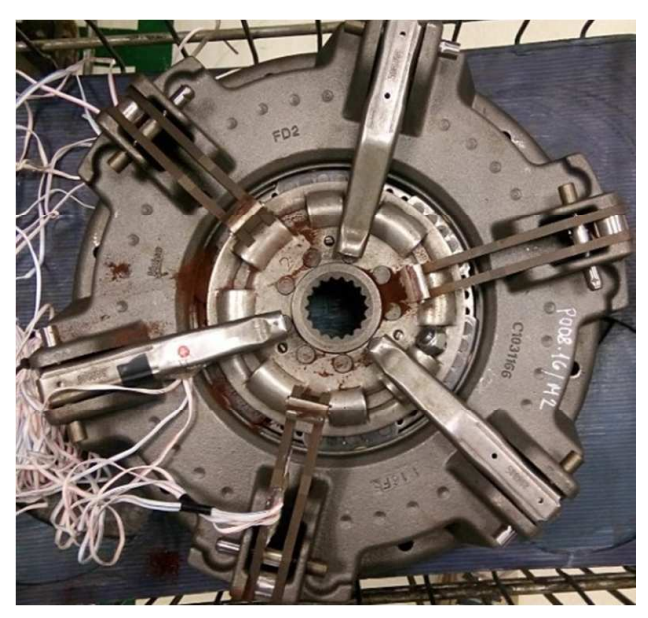

Figure 17. 